\title{
Intracellular Respiratory Dysfunction and Cell Injury in Short-term Anoxia of Rabbit Renal Proximal Tubules
}

\author{
Takehito Takano, Stephen P. Soltoff, Susan Murdaugh, and Lazaro J. Mandel \\ Department of Physiology and Machu Picchu Research Foundation, Duke University Medical Center, Durham, North Carolina 27710
}

\begin{abstract}
The effects of short-term anoxia and hypoxia were studied in a rabbit proximal renal tubule suspension in order to avoid the hemodynamic consequences of clamp-induced ischemia. The suspension was subjected to anoxia for $10-40 \mathrm{~min}$ and the effects on a number of cellular transport and respiratory parameters were monitored. Cellular respiration was measured upon addition of nystatin (Nys) to maximally stimulate $\mathrm{Na}$ pump activity. Mitochondrial respiration was measured in the tubules by addition of digitonin and ADP to obtain the state 3 respiratory rate. The release of lactate dehydrogenase (LDH) was measured as an index of plasma membrane damage. The cellular contents of $K$ and $\mathrm{Ca}$ were also measured. Results show that 10 and $20 \mathrm{~min}$ of anoxia partially inhibited Nys-stimulated and mitochondrial respiration, and partially decreased the $K$ contents, but all these effects were largely reversible after $20 \mathrm{~min}$ of reoxygenation. After $\mathbf{4 0} \mathrm{min}$ of anoxia and $\mathbf{2 0} \mathrm{min}$ of reoxygenation, all these variables remained irreversibly inhibited: Nys-stimulated respiration by $54 \%$, mitochondrial respiration by $50 \%$, $K$ content by $42 \%$, and LDH release was $40 \%$ of total. Ca content decreased slightly during anoxia, but increased up to fourfold during severe hypoxia; the excess $\mathrm{Ca}$ was released during the first $\mathbf{1 0} \mathrm{min}$ of reoxygenation. The degree of respiratory impairment was identical during anoxia or hypoxia, suggesting that $\mathrm{Ca}$ accumulation was not associated with the impairment. Decreasing the extracellular $\mathrm{Ca}$ to $2.5 \mu \mathrm{M}$ decreased $\mathrm{LDH}$ release significantly during anoxia, suggesting that plasma membrane damage during anoxia may be associated with increased intracellular free $\mathrm{Ca}$. Addition of Mg-adenosine triphosphate during anoxia dramatically improved recovery of all the measured parameters after the anoxic period.
\end{abstract}

\section{Introduction}

The pathologic effects of ischemia have been extensively studied in the kidney. By subjecting the kidney to ischemia of varying duration, investigators have been able to describe the many morphologic, physiologic, and biochemical alterations that occur in the kidney as a function of time (1-6). Upon deprivation of

Dr. Takano's present address is Department of Hygiene, Faculty of Medicine, Tokyo Medical and Dental University, Yushima 1-5-45, Bunkyo-ku, Tokyo 113, Japan; Dr. Soltoff's is Department of Biochemistry and Molecular Biology, Harvard University, 16 Divinity Avenue, Cambridge, MA 02139.

Received for publication 25 March 1985 and in revised form 28 August 1985.

J. Clin. Invest.

(c) The American Society for Clinical Investigation, Inc.

$0021-9738 / 85 / 12 / 2377 / 08 \quad \$ 1.00$

Volume 76, December 1985, 2377-2384 oxygen, proximal tubules rapidly lose $\mathrm{K}$ and gain $\mathrm{Na}(7,8)$, and decrease their ATP content $(9,10)$. Within 15 min of clampinduced ischemia, structural alterations are clearly observed in the form of cellular and mitochondrial swelling and irregular brush borders $(10,11)$. At the same time mitochondrial dysfunctions are clearly discernible (12). Subjecting the rat kidney to $25 \mathrm{~min}$ of ischemia produces further ultrastructural alterations that include the loss of brush border membranes (3), and these are accompanied by loss in transport function. All these malfunctions progress steadily with longer ischemia times $(4-6,10-$ 12), prompting extensive investigations to determine the course of reversibility from ischemia upon reoxygenation. Both morphology and function in the $S_{1}$ and $S_{2}$ segments recover from $25 \mathrm{~min}$ of ischemia, after $4 \mathrm{~h}$ of reflow $(3,13)$. After $35 \mathrm{~min}$ of ischemia, the morphology is reversible after $4 \mathrm{~h}$ of reflow but transport function remains impaired (5). Subjecting the rat kidney to $45 \mathrm{~min}$ of ischemia and longer causes irreversibility of transport $(1,2,6)$ and mitochondrial (6) function after even 24 $\mathrm{h}$ of reflow. Similar results have been obtained with other animals and other models of ischemia $(14,15)$. However, other studies seem to indicate that reversibility of structure is achievable after up to $60 \mathrm{~min}$ of ischemia $(4,11)$. Although many of these tubular alterations have been described in detail, the underlying causes for the dysfunctions remain unknown, especially the early intracellular events.

Most renal ischemia studies have been performed in animals in vivo by clamping the renal artery for varying amounts of time, after which reflow is initiated $(1-6,10-19)$. Thus, anoxia (or hypoxia) is produced simultaneously with a hemodynamic blockage which eliminates tubule perfusion, inhibiting both substrate support and removal of metabolic products. Therefore, when experimental maneuvers have been applied which ameliorate the effects of ischemia, it has been difficult to separate hemodynamic from tubular effects (16-19). In the present study, we utilized a suspension of proximal tubules obtained from the rabbit kidney $(20,21)$, which allowed the investigation of the effects of anoxia and hypoxia independently from the other consequences of clamp-induced ischemia. The suspension was subjected to hypoxia and anoxia of short duration (10-40 min) with subsequent reoxygenation in vitro, and the effects of these perturbations were evaluated on a number of cellular transport and respiratory parameters. Special attention was devoted to the role of $\mathrm{Ca}$ in the observed dysfunctions, because numerous investigators have suggested that $\mathrm{Ca}$ plays an important role in the irreversible phase of cellular injury $(4,6,19,22)$. In addition, the previously reported ameliorative effects of magnesium chloride-treated ATP $(\mathrm{Mg}-\mathrm{ATP})^{1}$ on ischemic cellular injury $(23,24)$ were evaluated in this preparation.

1. Abbreviations used in this paper: FCCP, carbonyl cyanide p-trifluoromethoxyhydrazone; $\mathrm{LDH}$, lactate dehydrogenase; Mg-ATP, magnesium chloride-treated ATP; TMPD, tetramethylphenylene diamine. 


\section{Methods}

\section{Preparation of renal tubule suspension}

Renal cortical tubules were prepared from female New Zealand White rabbits (Bunny Haven, Durham, NC; 3-4 kg wt) according to previously published methods $(21,25)$. In brief, after the animal was injected with heparin and anesthetized with ether, both kidneys were perfused at $37^{\circ} \mathrm{C}$ with a medium containing (in millimolar): $\mathrm{NaCl}$ (115), $\mathrm{NaHCO}_{3}(25)$, $\mathrm{NaH}_{2} \mathrm{PO}_{4}$ (2), $\mathrm{CaCl}_{2}$ (1), $\mathrm{KCl}(5), \mathrm{MgSO}_{4}$ (1), glucose (5), lactate (4), alanine (1), 0.6\% dextran, and mannitol (25) equilibrated with $95 \% \mathrm{O}_{2} /$ $5 \% \mathrm{CO}_{2}$ ( $\mathrm{pH}$ 7.4). After clearing the kidneys with this solution, perfusion was continued with the same solution to which collagenase was added $(124 \mathrm{U} / \mathrm{ml})$, followed by the original solution to clear the collagenase. The cortex was then excised, minced, dispersed, and washed three times with ice-cold medium containing (in millimolar): $\mathrm{NaCl}(140), \mathrm{NaH}_{2} \mathrm{PO}_{4}$ (2), $\mathrm{BaCl}_{2}(1), \mathrm{KCl}$ (5), $\mathrm{MgCl}_{2}$ (1), and Hepes (10) (pH 7.4). The use of $\mathrm{BaCl}_{2}$ throughout the preparative steps in the cold was instituted to obtain tubules with total calcium contents comparable to those found in the in vivo kidney (see Reference 26 for details). In order to remove nonvital single cells and cellular debris, one of the washes involved use of a Ficoll cushion (21). $\sim 90 \%$ of tubules in the resulting preparation were proximal in origin and their lumens were open. The final pellet was resuspended at a concentration of 6-8 $\mathrm{mg}$ protein/ml in the normal $\mathrm{NaCl}$ medium containing (in millimolar): $\mathrm{NaCl}$ (115), $\mathrm{NaHCO}_{3}$ (15), $\mathrm{NaH}_{2} \mathrm{PO}_{4}$ (2), $\mathrm{CaCl}_{2}$ (1), $\mathrm{KCl}(5), \mathrm{MgSO}_{4}$ (1), glucose (5), lactate (4), alanine (1), glutamate (5), malate (5), valerate (1), Hepes (10), $0.6 \%$ dextran, equilibrated with $95 \% \mathrm{O}_{2} / 5 \% \mathrm{CO}_{2}$ (pH 7.4).

\section{Instrumentation}

A specially designed cylindrical thermostated chamber previously described (21) was used to achieve anoxic or hypoxic conditions and to monitor the degree of hypoxia polarographically and spectrophotometrically. Anoxia was obtained by closing the chamber and allowing the tubules to consume all the oxygen in the solution. Hypoxia was achieved by equilibrating the surface of the suspension with gas mixtures of various $\mathrm{O}_{2}$ concentrations containing $5 \% \mathrm{CO}_{2}$. The $\mathrm{PO}_{2}$ of the solution was monitored with a Clark oxygen electrode to a level of $\sim 1 \%$, below which the electrode was not deemed to be accurate. Because hypoxia occurred at $\mathrm{PO}_{2}<1 \%$ (27), the degree of hypoxia was determined by monitoring the redox level of cytochrome oxidase in the tubules (21). A rapid scanning spectrophotometer was used for this purpose (28) and the absorption of cytochrome oxidase was measured at $605 \mathrm{~nm}$, with respect to 575 and $630 \mathrm{~nm}$ as reference wavelengths.

Most measurements of oxygen consumption rate $\left(\mathrm{QO}_{2}\right)$ were made in a smaller closed magnetically stirred thermostated chamber of $1.6 \mathrm{ml}$ in volume, using a Clark-type oxygen electrode.

\section{Experimental protocols}

MEASUREMENTS OF CELLULAR RESPIRATION AND MITOCHONDRIAL FUNCTION. Various parameters associated with respiratory function were examined to determine the degree of dysfunction created by anoxia and hypoxia:

Nystatin-stimulated respiration. Previous studies in our laboratory (7) have determined that addition of nystatin to proximal tubules leads to a rapid increase in $\mathrm{QO}_{2}$ caused by the entry of sodium from the extracellular medium and the consequent stimulation of $\mathrm{Na}, \mathrm{K}$-ATPase activity. The $\mathrm{QO}_{2}$ obtained with nystatin addition has been shown to equal the mitochondrial state 3 respiratory rate under normal conditions (7). Therefore, the nystatin-stimulated $\mathrm{QO}_{2}$ was used to measure the maximal rate of coupled respiration obtainable in the intact tubules before and after anoxia or hypoxia. Nystatin was added at a concentration of $160 \mathrm{mg} / \mathrm{ml}$.

Mitochondrial function. The state 3 respiratory rate $(7,29)$ of the tubular mitochondria was measured by permeabilization of the plasma membrane of intact tubules with digitonin $(400 \mu \mathrm{g} / \mathrm{ml})$ and addition of ADP $(400 \mu \mathrm{M})$. In these experiments, the tubules were suspended in a mitochondrial solution containing (in millimolar): $\mathrm{KCl}(120), \mathrm{KH}_{2} \mathrm{PO}_{4}$ (5), $\mathrm{MgSO}_{4}(1)$, glutamate (5), malate (5), valerate (1), Hepes (10), and
EGTA (2), pH 7.4. In some experiments, ADP was added prior to digitonin in order to test the permeability properties of the plasma membrane.

The rate of electron transfer from cytochrome $c$ to cytochrome oxidase in the respiratory chain of the tubular mitochondria was measured as the $\mathrm{QO}_{2}$ obtained in the presence of ascorbate $(1.1 \mathrm{mM})$, tetramethylphenylene diamine (TMPD) $(1.1 \mathrm{mM})$, and carbonyl cyanide $p$ trifluoromethoxyphenylhydrazone (FCCP) $(1.7 \mu \mathrm{M})$ following digitonin addition to tubules suspended in the aforementioned mitochondrial solution.

ANOXIA AND HYPOXIA EXPERIMENTS. Each experiment was initiated with a 20 -min preequilibration of the tubule suspension at $37^{\circ} \mathrm{C}$ in the normal $\mathrm{NaCl}$ solution bubbled with $95 \% \mathrm{O}_{2} / 5 \% \mathrm{CO}_{2}$. Anoxia or hypoxia was achieved in the cylindrical chamber, as described above, and was maintained for $10,20,30$, or $40 \mathrm{~min}$. After each period of anoxia, the tubule suspension was reoxygenated for $20 \mathrm{~min}$ in a shaker bath under a $95 \% \mathrm{O}_{2} / 5 \% \mathrm{CO}_{2}$ atmosphere at $37^{\circ} \mathrm{C}$. Samples were taken from the suspension at three times during each experiment: immediately before anoxia, immediately after anoxia, and after reoxygenation. For each experiment, a tubule suspension was continuously maintained in parallel under oxygenated conditions for the duration of the experiment. Samples were obtained from this suspension at the same times, and the same variables were measured and used as control values. Percent impairment of each function was calculated using the respective control value obtained at the same time for each experiment. At each sampling time, cellular respiration and mitochondrial function were tested as described above, and the percent lactate dehydrogenase (LDH) released from the cells as well as total cellular calcium and potassium contents were measured.

In one series of experiments, the effects of low $\mathrm{Ca}$ were tested by replacing the $1 \mathrm{mM} \mathrm{CaCl}_{2}$ in the normal $\mathrm{NaCl}$ solution with $2.5 \mu \mathrm{M}$ $\mathrm{CaCl}_{2}$. In another experimental group, $\mathrm{Mg}-\mathrm{ATP}(1: 1)$ was added to the suspension in five aliquots, each of which added a concentration of 0.2 $\mathrm{mM}$ to the solution, at 10 -min intervals during $40 \mathrm{~min}$ of anoxia. $\mathrm{Mg}$ ATP was added just before anoxia (time " 0 ") and after 10, 20, 30, and $40 \mathrm{~min}$ of anoxia. No further additions of $\mathrm{Mg}$-ATP were made during reoxygenation.

\section{Chemical assays}

Total cell Ca content and total cell potassium content were measured on a perchloric acid extract of the tubule cells using a Perkin-Elmer (model 460) atomic absorption spectrophotometer (Perkin-Elmer Corp., Norwalk, CT). LDH was assayed according to the procedure of Bergmeyer et al. (30). Released LDH from the cells was expressed as percent of total LDH (released LDH plus nonreleased LDH in the cells). Total LDH was measured after plasma membrane disruption by freeze thawing. Protein was measured by the biuret method (31).

\section{Materials}

Collagenase (type 4) was obtained from Sigma Chemical Co. (St. Louis, Mo.) or Worthington Biochemical Corp. (Freehold, NJ). Digitonin, nystatin (mycostatin), Hepes, ATP, and ADP were obtained from Calbiochem-Behring Corp. (LaJolla, CA). Dextran T-40 and Ficoll were purchased from Pharmacia Fine Chemicals (Piscataway, NJ). Ouabain, and Tris were obtained from Sigma Chemical Co. All other chemicals were reagent grade. Nystatin was dissolved in dimethyl sulfoxide.

\section{Statistics}

All values are reported as the mean \pm standard error. For statistical analysis of the differences between mean values, the unpaired Student's $t$ test was used. In the anoxia with Mg-ATP experiment, the paired Student's $t$ test was used.

\section{Results}

Respiratory dysfunction produced by anoxia. Under control conditions, the $\mathrm{QO}_{2}$ was $22.7 \pm 1.4 \mathrm{nmol}$ of $\mathrm{O}_{2} \cdot \mathrm{min}^{-1} \cdot \mathrm{mg}$ of 
protein $^{-1}$, and nystatin addition increased this rate by $39 \pm 1 \%$ to $32.0 \pm 1.5 \mathrm{nmol} \mathrm{O}_{2} \cdot \mathrm{min}^{-1} \cdot \mathrm{mg}$ of protein ${ }^{-1}(n=20)$. The nystatin-stimulated $\mathrm{QO}_{2}$ was progressively inhibited as the duration of anoxia was increased. Examination of the nystatinstimulated rate immediately after reoxygenation showed a large degree of impairment even after $10 \mathrm{~min}$ of anoxia (Fig. $1 A$ ), linearly increasing to $63 \%$ impairment after $40 \mathrm{~min}$ of anoxia. $20 \mathrm{~min}$ of reoxygenation allowed a fairly good recovery of the tubules exposed to 10 and $20 \mathrm{~min}$ of anoxia (Fig. $1 \mathrm{~B}$ ). However, 30 and 40 min of anoxia still elicited $40 \%$ and $55 \%$ impairment, respectively, even after this period of reoxygenation.

The percentage of LDH released from the tubules increased with the duration of anoxia (Fig. $1 A$ ). The release was relatively small $(<10 \%)$ when the duration of anoxia was 20 min or less, but increased rapidly with longer anoxia times. Most of this release occurred during anoxia, inasmuch as reoxygenation caused no further significant increase in \%LDH released (Fig. $1 B$ ).

In another series of experiments, parallel measurements were made of nystatin-stimulated $\mathrm{QO}_{2}$ and mitochondrial respiratory function. The latter was measured under two conditions (see Methods): ADP-stimulated $\mathrm{QO}_{2}$ in the presence of digitonin in a $\mathrm{KCl}$ medium (coupled respiration), and FCCP-stimulated $\mathrm{QO}_{2}$ in the presence of ascorbate and TMPD (uncoupled respiration). Addition of ADP prior to digitonin elicited no significant increase in $\mathrm{QO}_{2}$ either prior to anoxia or after $10,20,30$, or $40 \mathrm{~min}$ of anoxia (results not shown). Subsequent addition of digitonin (in the presence of ADP) stimulated respiration to the mitochondrial state 3 rate. These results indicate that plasma membranes of the cells containing ADP-responsive mitochondria retain their impermeability to ADP even after the anoxic insult.

The results of these experiments are shown in Fig. 2, plotted as the percent control value after being subjected to the indicated time in anoxia and $20 \mathrm{~min}$ of recovery. It appears that the cells recover almost complete respiratory function after 10 and 20 min of anoxia, as expected from Fig. 1. However, after 30 and $40 \mathrm{~min}$ of anoxia, a pattern of partial irreversibility of function begins to emerge within the time course of these experiments. After $30 \mathrm{~min}$ of anoxia, the nystatin-stimulated $\mathrm{QO}_{2}$ demonstrated a significantly higher degree of impairment than mitochondrial-respiratory function, as measured by the ADP- and FCCP-stimulated $\mathrm{QO}_{2}$ 's. This suggests that the primary respi-

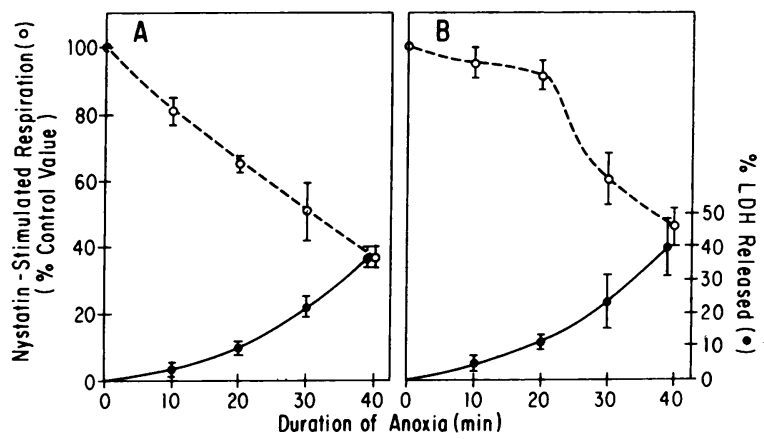

Figure 1. Percent impairment of maximum cellular respiratory rate stimulated by nystatin $(0)$ and percent $\mathrm{LDH}$ release $(\bullet)$ as a function of the duration of anoxia measured $(A)$ immediately after anoxia and $(B)$ after 20 min of reoxygenation $(n=6)$. The percent $\mathrm{LDH}$ released by control tubules continuously oxygenated for up to $60 \mathrm{~min}$ was $4.1 \pm 0.4 \%$.

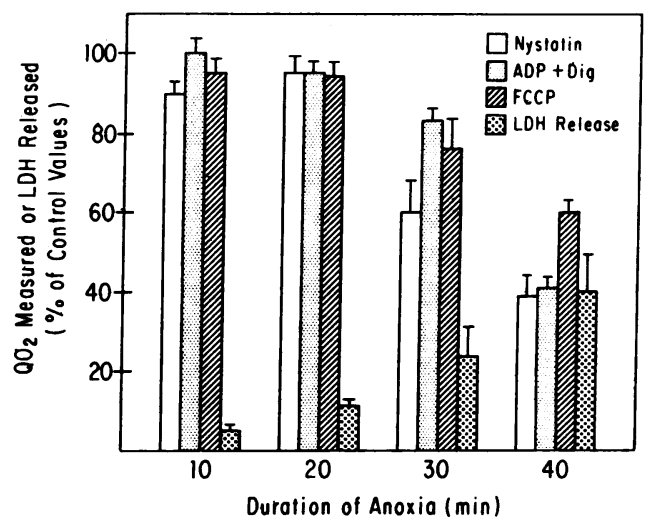

Figure 2. Percent impairment of nystatin-stimulated respiration, mitochondrial function measured as ADP (+ digitonin)- and FCCP-stimulated respiration, and LDH release as a function of the duration of anoxia. Each variable was measured after $20 \mathrm{~min}$ of reoxygenation ( $n$ =6). The values for nystatin-, ADP-, and FCCP-stimulated $\mathrm{QO}_{2}$ 's under control conditions were, respectively, $32.0 \pm 1.5,35.6 \pm 1.6$, and $113.8 \pm 4.6 \mathrm{nmol} \mathrm{O} \mathrm{O}_{2} \cdot \mathrm{min}^{-1} \cdot \mathrm{mg}$ protein ${ }^{-1}$.

ratory impairment in this case may be due to the loss of adenine nucleotides from the cells and subsequent decrease of Na pump stimulation (see Discussion). After $\mathbf{4 0} \mathrm{min}$ of anoxia, the impairment in the nystatin- and the ADP-stimulated $\mathbf{Q O}_{2}$ 's are very similar to one another, and both are significantly larger than that of the FCCP-stimulated $\mathrm{QO}_{2}$. Because the rate of electron flow through cytochrome oxidase is impaired less than the ADP-stimulated $\mathbf{Q O}_{2}$, it appears that an inhibition in the mitochondrial ADP-ATP translocase may also become apparent under these conditions (see Discussion). Therefore, differential deterioration of cellular function is observed as the duration of anoxia is increased. Almost complete reversibility is observed after 10 and $20 \mathrm{~min}$ of anoxia; the effects of adenine nucleotide loss are observed after $30 \mathrm{~min}$, and the mitochondrial dysfunctions become rate-limiting after $\mathbf{4 0} \mathrm{min}$ of anoxia.

Cellular $\mathrm{K}^{+}$content during anoxia and recovery. The $\mathrm{K}^{+}$ content of the tubules prior to anoxia was $300 \pm 7 \mathrm{nmol} / \mathrm{mg}$ of protein. Upon initiation of anoxia, the tubular cells rapidly lose their $\mathrm{K}^{+}$owing to the inhibition in ATP production $(7,8)$. After 10 min of anoxia the $\mathrm{K}^{+}$content was only $40 \%$ of control, and longer periods of anoxia decreased this content another $5-10 \%$ (Fig. 3). 20 min of reoxygenation produced complete recovery of $\mathrm{K}^{+}$content after 10 min of anoxia and almost complete recovery after $20 \mathrm{~min}$. Recovery was significantly less after 30 and $40 \mathrm{~min}$ of anoxia. An additional $20 \mathrm{~min}$ of reoxygenation did not appreciably change this situation (results not shown).

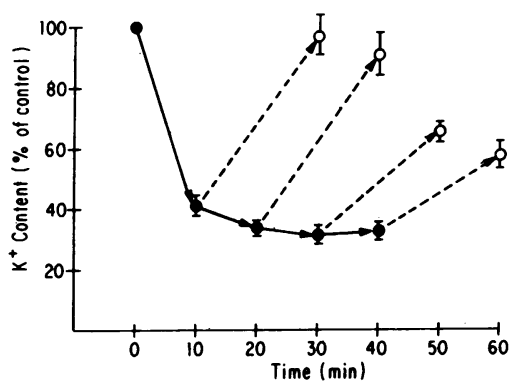

Figure 3. Loss and recovery of $\mathrm{K}^{+}$content in the cells. (๑) Values after anoxia; (O) values after 20 min of reoxygenation $(n=5)$. 
Role of calcium in the respiratory dysfunction induced by anoxia and hypoxia. The role of calcium in the anoxia-induced respiratory dysfunction was investigated using two different approaches. First, the relationship between total calcium accumulation and respiratory dysfunction was studied. Preliminary experiments suggested that renal tubules subjected to hypoxia, rather than anoxia, accumulated calcium. These results prompted an investigation into the relationship between $\mathrm{Ca}$ accumulation and the degree of hypoxia. The latter was measured spectrophotometrically by the percent oxidation of cytochrome oxidase in the tubular mitochondria (see Methods). During normoxia, cytochrome oxidase has a high affinity for $\mathrm{O}_{2}$ and is therefore almost $100 \%$ oxidized (21), whereas anoxia leads to complete reduction ( $0 \%$ oxidation) of this cytochrome. Hypoxia is present when the oxygen pressure within the cells is insufficient to maintain cytochrome oxidase fully oxidized, leading to partial reduction and impairment of electron flow (31). In the present experiments, this was achieved by decreasing the $\mathrm{PO}_{2}$ of the bathing medium below $1 \%$. Under normoxic conditions, total cellular calcium content average $16.6 \pm 0.5 \cdot \mathrm{nmol} / \mathrm{mg}$ of protein $(n=20)$. As shown in Fig. 4, no change in calcium content occurred until the $\mathrm{PO}_{2}$ was decreased sufficiently to create severe hypoxia, as measured by a partial reduction of cytochrome oxidase to the $10-30 \%$ oxidation level. This led to a large accumulation of calcium. In contrast, a slight calcium release was actually observed during anoxia.

The calcium accumulation observed during severe hypoxia was studied as a function of the duration of hypoxia, as shown in Fig. 5. Calcium content was seen to increase linearly with time, reaching a maximum level after $30 \mathrm{~min}$ of hypoxia. This process was rapidly reversible in all cases, since the tubules regained their original calcium content within $10 \mathrm{~min}$ of reoxygenation.

The differences between anoxia and hypoxia were used to determine whether calcium accumulation affected the observed respiratory dysfunction. As seen in Table I, the inhibition of nystatin-stimulated respiration was identical whether the tissue was subjected to severe hypoxia $(30 \mathrm{~min})$, increasing its total calcium content by $250 \%$, or to anoxia ( $30 \mathrm{~min}$ ), with unchanged total calcium. Furthermore, the hypoxia-induced calcium accumulation was abolished by the addition of $3 \mu \mathrm{M}$ ruthenium

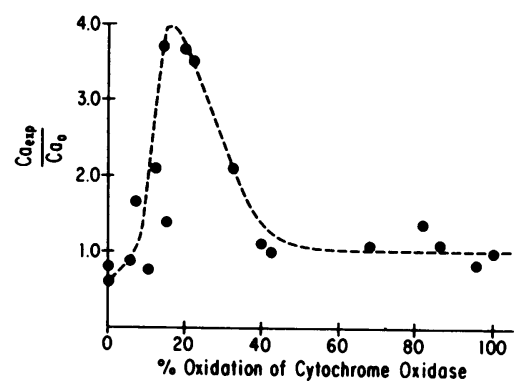

Figure 4. Cellular calcium content of the renal tubules as a function of the severity of hypoxia. Variable degrees of hypoxia were achieved as described in Methods, and these were monitored spectrophotometrically as the percent oxidation of cytochrome oxidase. Calcium content is expressed as the ratio of experimental to control, in which the latter was measured in a paired experiment under normoxia. Each experimental point represents a separate paired experiment in which the tubules were subjected to $\mathbf{3 0}$ min of hypoxia under the stated conditions. The dashed line was drawn by eye.

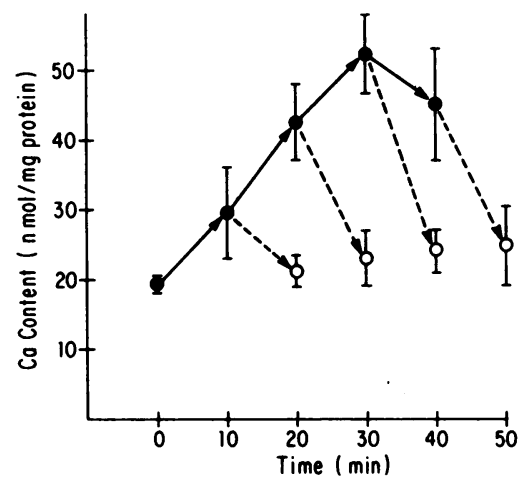

Figure 5. Ca content of the tubular cells subjected to severe hypoxia for the indicated time, followed by $10 \mathrm{~min}$ of reoxygenation. (๑) Values after hypoxia; $(0)$ values after reoxygenation $(n=5)$.

red (Table I), an inhibitor of mitochondrial calcium uptake, with no significant ameliorative effect on nystatin-stimulated respiration after hypoxia. Two conclusions may be drawn from these results: ( $a$ ) calcium accumulates in the mitochondria during severe hypoxia but not during anoxia; and $(b)$ this accumulation is unrelated to the respiratory dysfunction elicited by short-term hypoxia or anoxia.

The second approach to study the involvement of calcium with the respiratory dysfunctions induced by anoxia was to vary the external calcium concentration in the extracellular medium during anoxia. Decreasing the extracellular calcium from $1 \mathrm{mM}$ to $2.5 \mu \mathrm{M}$ drastically reduced the percent LDH loss from the tubules during $30 \mathrm{~min}$ of anoxia (Fig. 6). However, the low calcium medium appeared to be harmful to the tubules during reoxygenation, since the percent $L D H$ release increased significantly in this medium whereas no significant change was observed after reoxygenation in $1 \mathrm{mM}$ calcium (Figs. $1 A$ and $B$, and 6).

The respiratory responses of the tubules were not significantly different in the low or normal calcium medium immediately after 30 min of anoxia (Fig. $7 \mathrm{~A}$ ). There was, however, a significant inhibition in the recovery of the ADP response after reoxygenation in the low calcium medium (Fig. 7 B). Therefore, it

Table I. Cellular Calcium Accumulation and Respiratory Dysfunction Induced by Hypoxia and Anoxia

\begin{tabular}{lllll}
\hline & Control & $\begin{array}{l}\text { Severe } \\
\text { hypoxia }\end{array}$ & Anoxia & $\begin{array}{l}\text { Severe } \\
\text { hypoxia } \\
\text { + ruthenium } \\
\text { red }\end{array}$ \\
\hline $\begin{array}{c}\text { Ca content } \\
\text { (nmol/mg protein) }\end{array}$ & $16.6 \pm 0.5$ & $40.6 \pm 6.8^{*}$ & $15.5 \pm 1.6$ & $16.1 \pm 1.2$ \\
$\begin{array}{c}\text { Nystatin-stimulated } \\
\text { respiration }(\text { nmol } \\
O_{2} / \text { min.mg } \\
\text { protein) }\end{array}$ & $32.0 \pm 1.5$ & $13.0 \pm 1.5$ & $13.8 \pm 0.7$ & $16.3 \pm 1.7$ \\
$n \quad$ & 20 & 8 & 7 & 5 \\
\hline
\end{tabular}

The tubules were subjected to hypoxia or anoxia as described in Methods and Fig. 4. The duration of hypoxia or anoxia was $30 \mathrm{~min}$ followed by $20 \mathrm{~min}$ of reoxygenation.

$* P<0.01$. 


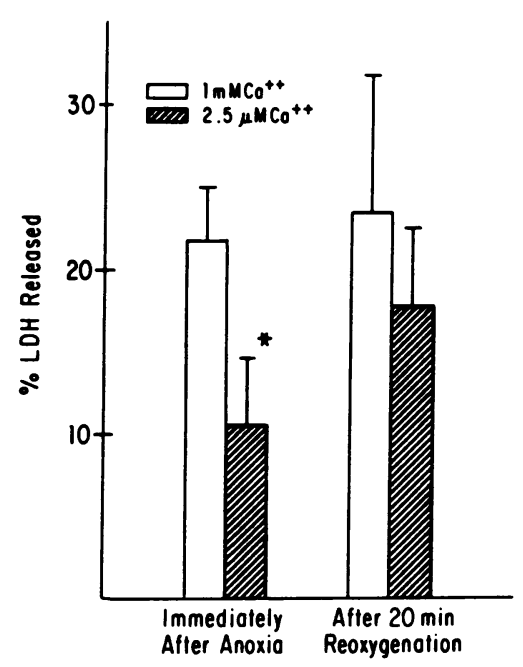

Figure 6. Percent LDH released after $30 \mathrm{~min}$ of anoxia in solutions containing either $1 \mathrm{mM} \mathrm{Ca}^{++}$or $2.5 \mu \mathrm{M} \mathrm{Ca}^{++}$. There is a significant decrease $\left({ }^{*} P<0.01\right)$ observed immediately after anoxia in the low calcium medium $(n=5)$.

appears that low extracellular calcium may play a mildly protective role during anoxia but be somewhat deleterious during reoxygenation.

Protective effect of $M g-A T P$. Addition of Mg-ATP to the bathing medium provided dramatic protection against the anoxia-induced dysfunctions. In the presence of Mg-ATP, the percent $\mathrm{LDH}$ release after $40 \mathrm{~min}$ of anoxia was decreased by $75 \%$ and this was maintained during reoxygenation (Fig. 8). Some protection of respiratory function was evident immediately after $40 \mathrm{~min}$ of anoxia (Fig. $9 \mathrm{~A}$ ), in that the nystatin response was significantly higher. The most dramatic effect of Mg-ATP was on the recovery from anoxia, which was significantly improved in all the measured parameters (Fig. $9 \mathrm{~B}$ ).

\section{Discussion}

Functional impairments in respiration and ion content were obtained by subjecting a suspension of proximal tubules to vary-

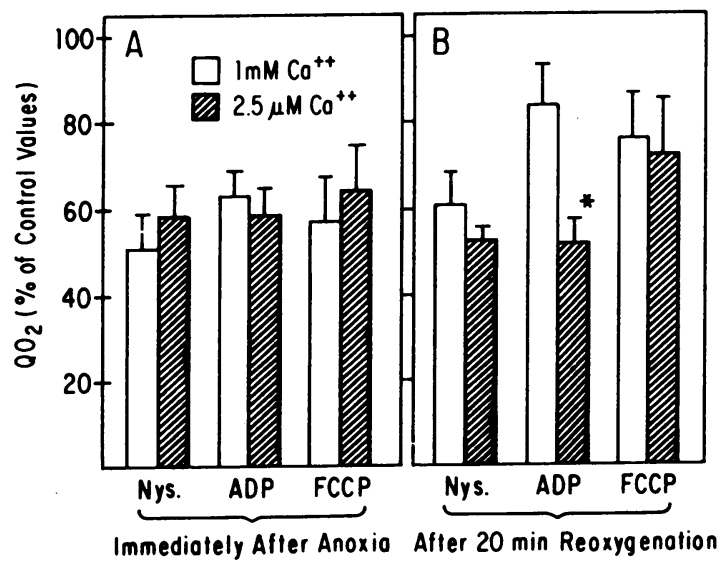

Figure 7. Respiratory responses of tubules after $30 \mathrm{~min}$ of anoxia in solutions containing either $1 \mathrm{mM} \mathrm{Ca}{ }^{++}$or $2.5 \mu \mathrm{M} \mathrm{Ca}^{++}$. No significant change was observed immediately after anoxia. A significant inhibition $\left({ }^{*} P<0.01\right)$ was observed in the recovery of the ADP response after reoxygenation $(n=5)$.

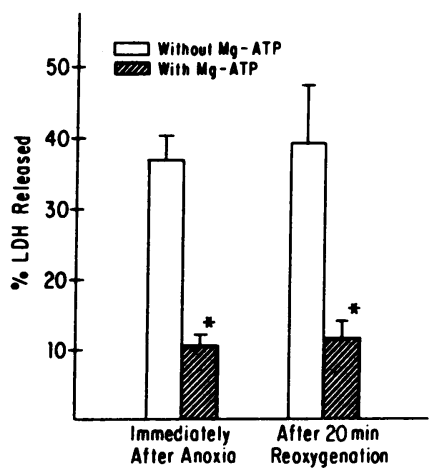

ing times of short-term anoxia and reoxygenation. The impairments were significant even after $10 \mathrm{~min}$ of anoxia and increased progressively as the duration of anoxia was prolonged. These results are consistent with those of Harris et al. (7), who found that the effects of anoxia on tubular respiration were immediately reversible only up to $4 \mathrm{~min}$ of anoxia. In the present study, the effects of 10 and 20 min of anoxia could be largely reversed by $20 \mathrm{~min}$ of reoxygenation. Longer times of anoxia created impairments that were not reversible within $20 \mathrm{~min}$ of reoxygenation. Longer reoxygenation times were explored in some cases (up to $\mathbf{4 0} \mathrm{min}$ ) with little added improvement in function (results not shown). Similar types of results regarding reversibility of function have been obtained by a variety of investigators using renal artery occlusion in the intact animal (see Introduction).

The present studies allow the identification of a sequence of impairments that occur during the early stages of anoxia, which may persist for a long time during reoxygenation, and may be a determinant of long-term reversibility of the proximal tubules after an anoxic episode. The release of $\mathrm{LDH}$ progressively increases with duration of anoxia, indicating that plasma membrane damage occurs during anoxia and becomes more prevalent as the duration of anoxia increases. This result is consistent with the loss of brush border observed during ischemia $(3-5,10,11$, 13). It is important to note that all the LDH release occurs during anoxia (Fig. $1 A$ and $B$ ) and, therefore, resealing of plasma membranes seems to occur rapidly after reoxygenation, as evidenced in the morphologic studies of Venkatachalam et al. (13). This

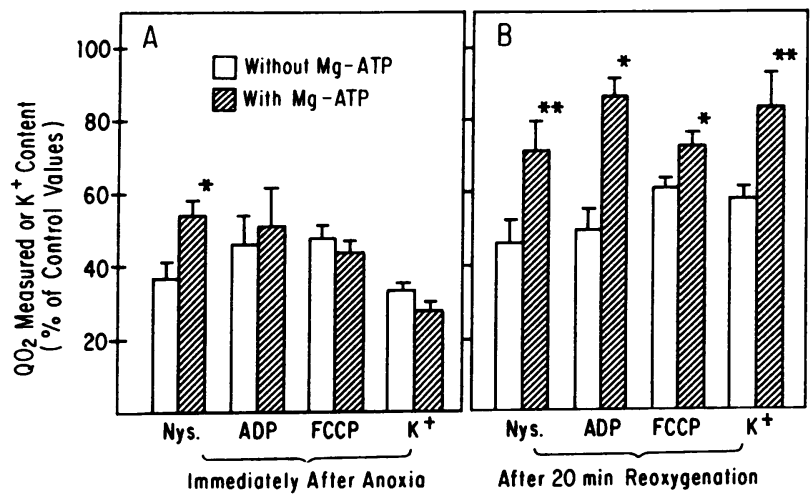

Figure 9. Effect of Mg-ATP addition on respiratory function and $\mathrm{K}^{+}$ content of tubules subjected to $\mathbf{4 0} \mathrm{min}$ of anoxia. There was a significant $\left({ }^{*} P<0.01\right)$ improvement in nystatin-stimulated respiration immediately after anoxia. All measured functions improved significantly $(* * P<0.05)$ after reoxygenation $(n=4)$. 
resealing process is also evidenced by the impermeability of plasma membranes to ADP and the ability of the cells to reaccumulate potassium (Fig. 3).

A small but significant degree of irreversibility is observed in nystatin-stimulated respiration after 10 and $20 \mathrm{~min}$ of anoxia, but a large impairment becomes manifest after 30 and 40 min of anoxia (Fig. $1 B$ ). Nystatin increases monovalent ion permeability through the plasma membrane, causing sodium to enter the cells and thus stimulate $\mathrm{Na}, \mathrm{K}-\mathrm{ATPase}$ activity, with a consequent increase in ATP turnover and respiration (7). Under normal conditions, nystatin stimulates respiration to the maximum rate at which the tubular mitochondria are capable of producing ATP. The $\mathrm{QO}_{2}$ achieved with ADP in the presence of digitonin (mitochondrial state 3 rate) is normally identical to the nystatin-stimulated $\mathrm{QO}_{2}$ (7). Therefore, the inhibition in nystatin-stimulated $\mathrm{QO}_{2}$ observed after anoxia could be due to impairment in mitochondrial function, inhibited $\mathrm{Na}, \mathrm{K}-\mathrm{ATPase}$ activity, and/or limited availability of adenine nucleotides. Mitochondrial function was tested independently as the ADP- and FCCP- stimulated $\mathrm{QO}_{2}$ 's (Fig. 2) and found to be normal after 10 and $20 \mathrm{~min}$ of anoxia. Progressive impairment of mitochondrial function was found after 30 and 40 min of anoxia, similar to that observed by other investigators $(6,12)$. However, after 30 min of anoxia, the ADP-stimulated $\mathrm{QO}_{2}$ was impaired significantly less than the nystatin-stimulated $\mathrm{QO}_{2}(P<0.01)$, suggesting that the mitochondrial dysfunction may not be the principal cause of the severe inhibition of the nystatin response. The $\mathrm{Na}, \mathrm{K}-\mathrm{ATPase}$ activity was not tested in these experiments independently from the availability of ATP; however, the ability of the tubules to partially reaccumulate potassium (Fig. 3) suggests that the function of this enzyme may not be appreciably altered. Preliminary experiments (32) indicate that the loss of adenine nucleotides from the tubules may be the most important factor limiting nystatin-stimulated respiration after $30 \mathrm{~min}$ of anoxia. The tubular contents of ATP and ADP decrease dramatically (55-75\%) and hypoxanthine levels increase by an order of magnitude after 30 or $40 \mathrm{~min}$ of anoxia followed by $20 \mathrm{~min}$ of reoxygenation (32). Under these conditions, mitochondrial respiration and the rate of ATP production could be limited by the availability of ADP. Simultaneously, the increase in $\mathrm{Na}, \mathrm{K}$ ATPase activity elicited by nystatin would be limited by the cellular ATP concentration, because ATP appears to be ratelimiting for this enzyme in the intact tubule (33). In this manner, the limited availability of adenine nucleotides could cause reduction of both the Na,K-ATPase activity and the mitochondrial respiratory response. The loss of adenine nucleotides due to anoxia has also been found in a variety of other tissues (22).

After $40 \mathrm{~min}$ of anoxia, the impairment in mitochondrial state 3 respiration (ADP response) is equal to that of nystatinstimulated $\mathrm{QO}_{2}$. This decrease in mitochondrial function could fully account for the decline in nystatin-stimulated $\mathrm{QO}_{2}$. However, an important role in this dysfunction may also be attributed to the aforementioned depletion in cellular adenine nucleotides. As shown in Fig. 2, the ADP response is more severely inhibited than the FCCP response at $40 \mathrm{~min}$, suggesting an inhibition in ADP-ATP translocase activity (34). Various other investigators have found similar mitochondrial defects in the kidney after anoxia whether applied in vivo or in vitro $(6,12,34-36)$.

Therefore, the present studies suggest that some of the earliest dysfunctions caused by anoxia involve plasma membrane damage, the loss of adenine nucleotides from the proximal tubular cells, and the impairment of mitochondrial function. The bio- chemical mechanisms responsible for these dysfunctions still remain largely unknown, although attempts have been made to attribute them to cellular calcium accumulation $(6,17-19,22)$, ATP depletion $(23,24,36)$, increase in fatty acyl-CoA concentration (22), breakdown of membrane phospholipids (37), as well as other possible mechanisms. In this study the first two of these factors were investigated to determine their role in the dysfunctions produced by anoxia.

In a variety of tissues, such as liver $(22,34)$, cardiac muscle $(38,39)$, and kidney $(6,17-19)$, calcium accumulation in the mitochondria has been observed during reoxygenation after ischemia. This accumulation is often coincident with irreversible cell damage, leading to suggestions from various groups that the accumulation causes the irreversible damage $(6,22,37,38)$. In the present studies, the observation of cellular calcium accumulation during hypoxia was initially puzzling until the more comprehensive experiments shown in Fig. 4 were performed. Because ruthenium red prevented this accumulation (Table I), it seems that the excess calcium is taken up by the mitochondria (26). This uptake process requires mitochondrial energization, as attested by the actual loss of calcium which occurs when complete reduction of cytochrome oxidase is achieved (anoxia). During normoxia, the mitochondrial calcium content is maintained in steady state because the rate of passive calcium entry into the cells is equal to the rate of active extrusion, probably through the Ca-ATPase $(40,41)$. This balance is maintained even during mild hypoxia, down to $\sim 40 \%$ oxidation of cytochrome oxidase. Severe hypoxia, however, seems to upset this balance between cellular influx and extrusion, most likely because of the limited mitochondrial capacity to produce ATP under these conditions (31). Cellular calcium entry would continue, but the Ca-ATPase would not be able to maintain the efflux rate due to the limited availability of ATP. This situation would be expected to cause an elevation of cytosolic free calcium, leading to mitochondrial uptake as long as this organelle remains minimally energized. Mitochondria have been shown to take up calcium at the expense of ATP production under conditions of limited energy availability $(42,43)$.

The calcium accumulation observed during hypoxia was fully reversible within $10 \mathrm{~min}$ of reoxygenation even after $40 \mathrm{~min}$ of low oxygen availability (Fig. 5). This finding suggests that reduced levels of ATP can maintain a normal cellular calcium extrusion rate. Mitochondrial calcium accumulation did not cause any additional damage to the cells in that no difference was observed in the degree of respiratory impairment produced by hypoxia or anoxia (Table I). Therefore, it seems that mitochondrial calcium accumulation is not one of the limiting factors involved in the early stages of anoxia- or hypoxia-induced respiratory dysfunctions. These results are consistent with those of Miyohara et al. (36), who subjected isolated liver mitochondria to anoxia and found increasing membrane damage with time in anoxia, leading to respiratory dysfunctions in the absence of calcium.

The clear difference in cellular calcium content between anoxia and hypoxia may be utilized to determine which of these conditions are actually present at the cellular level when the whole kidney is subjected to ischemia. For example, in the studies of Wilson et al. (6), the mitochondrial calcium content immediately after removal of the arterial clamp was elevated as compared to controls. This may indicate that the cells were subjected to hypoxia rather than anoxia, under these conditions.

The effects of calcium concentration during anoxia were probed indirectly by lowering the extracellular calcium from 1 
$\mathrm{mM}$ to $2.5 \mu \mathrm{M}$. During anoxia, the inhibition of the Ca-ATPase and mitochondrial calcium buffering presumably causes an increase in cytosolic free calcium, which is dependent on the extracellular calcium concentration. Therefore, $2.5 \mu \mathrm{M}$ extracellular calcium would be expected to cause a smaller increase in intracellular free calcium than would exposure to $1 \mathrm{mM} \mathrm{Ca}$. The lower calcium concentration was found to protect the plasma membrane, reducing LDH leakage measured immediately after anoxia by $50 \%$ (Fig. 6). However, the lower calcium did not protect any of the measured respiratory parameters from anoxia (Fig. $7 \mathrm{~A}$ ). Low extracellular calcium proved to be deleterious to function during reoxygenation, because $\mathrm{LDH}$ release increased during this period (Fig. 6) and recovery of ADP-stimulated respiration was blunted (Fig. 7 B). Thus, the role of calcium in these dysfunctions appears to be complex. The protection of the plasma membrane by low calcium may indicate that the increase in cytosolic free calcium that would normally be expected to occur during anoxia (44), is associated with the observed damage to the plasma membrane. Conversely, these results suggest that the cytosolic free calcium does not appear to mediate the respiratory dysfunctions elicited during anoxia. These results are consistent with those of Miyahara et al. (36) who elicited respiratory dysfunctions in isolated liver mitochondria exposed to in vitro anoxia in the absence of calcium. These dysfunctions were similar to those observed in kidney mitochondria after clampinduced ischemia $(6,12)$. Extracellular calcium seems to be protective during reoxygenation (Figs. 6 and $7 \mathrm{~B}$ ), and this confirms our previous observations (26) that long-term incubation of proximal tubules in a low-calcium medium is deleterious to their function.

The effects of extracellular addition of Mg-ATP were tested in that various investigators $(23,24)$ have observed significant improvements in the ability of the kidney to recover from ischemia under these conditions. In the present experiments, the enhanced recovery from anoxia was dramatic. It is presently unclear whether the improvements are due to the extracellular ATP or due to the increased intracellular ATP levels found when ATP is added extracellularly $(45,46)$. It is also not presently known how this increase in intracellular ATP occurs, because no transport system for ATP has been described for proximal tubules. However, it is clear that Mg-ATP dramatically protects the plasma membrane during both anoxia and reoxygenation (Fig. 8). Interestingly, only the nystatin-stimulated respiration was significantly protected during anoxia (Fig. 9), consistent with the notion that extracellular Mg-ATP helps preserve higher intracellular levels of adenine nucleotides. In the presence of $\mathrm{Mg}$ ATP, the recovery during reoxygenation was dramatically improved. All the respiratory parameters and the $\mathrm{K}^{+}$content recovered significantly better in the presence than in the absence of Mg-ATP, which is consistent with findings (36) that liver mitochondria recovered from anoxia dramatically better in the presence of added ATP. These results emphasize the importance of the preservation of intracellular adenine nucleotides in the recovery from anoxia. By implication, the loss of adenine nucleotides appears to be one of the most important factors which contribute to the cellular damage induced by anoxia.

\section{Acknowledgments}

Dr. Takano was supported during his stay at Duke University by a grant from the Japanese Ministry of Education. This work was supported by National Institutes of Health grant AM26816 to Dr. Mandel.

\section{References}

1. Arendshorst, W. J., W. F. Finn, and C. W. Gottschalk. 1975. Pathogenesis of acute renal failure following temporary renal ischemia in the rat. Circ. Res. 37:558-568.

2. Anderson, R. J., J. A. Gordon, J. K. Kim, L. N. Peterson, and P. A. Gross. 1982. Renal concentration defect following nonoliguric acute renal failure in the rat. Kidney Int. 21:583-591.

3. Venkatachalam, M. A., D. B. Bernard, J. F. Donohoe, and N. G. Levinsky. 1978. Ischemic damage and repair in the rat proximal tubule: Differences among the $S_{1}, S_{2}$ and $S_{3}$ segments. Kidney Int. 14:31-49.

4. Trump, B. F., I. K. Berezesky, and R. A. Cowley. 1982. The cellular and subcellular characteristics of acute and chronic injury with emphasis on the role of calcium. In Pathophysiology of Shock, Anoxia, and Ischemia. R. A. Cowley and B. F. Trump, editors. Williams \& Wilkins, Baltimore. 6-46.

5. Johnston, P. A., H. Rennke, and N. G. Levinsky. 1984. Recovery of proximal tubular function from ischemic injury. Am. J. Physiol. 246: F159-F166.

6. Wilson, D. R., P. E. Arnold, T. J. Burke, and R. W. Schrier. 1984. Mitochondrial calcium accumulation and respiration in ischemic acute renal failure in the rat. Kidney Int. 25:519-526.

7. Harris, S. I., R. S. Balaban, L. Barrett, and L. J. Mandel. 1981. Mitochondrial respiratory capacity and $\mathrm{Na}^{+}$- and $\mathrm{K}^{+}$-dependent adenosine triphosphatase-mediated ion transport in the intact renal cell. $J$. Biol. Chem. 256:10319-10328.

8. Mason, J., F. Beck, A. Doreg, R. Rick, and K. Thurau. 1981. Intracellular electrolyte composition following renal ischemia. Kidney Int. 20:61-70.

9. Balaban, R. S., L. J. Mandel, S. Soltoff, and J. M. Storey. 1980. Coupling of active ion transport and aerobic respiratory rate in isolated renal tubules. Proc. Natl. Acad. Sci. USA. 77:447-451.

10. Kahng, M. W., I. K. Berezesky, and B. F. Trump. 1978. Metabolic and ultrastructural response of rat kidney cortex to in vitro ischemia. Exp. Mol. Pathol. 29:183-198.

11. Glaumann, B., H. Glaumann, I. K. Berezesky, and B. F. Trump. 1977. Studies on cellular recovery from injury. II. Ultrastructural studies on the recovery of the pars convoluta of the proximal tubule of the rat kidney from temporary ischemia. Virchows' Arch. B Cell Pathol. 24:118.

12. Mergner, W. J., L. Marzella, C. Mergner, M. W. Kahng, M. W. Smith, and B. F. Trump. 1977. Studies on the pathogenesis of ischemic cell injury. VII. Proton gradient and respiration of renal tissue cubes, renal mitochondrial and submitochondrial particles following ischemic cell injury. Beitr. Pathol. 161:230-243.

13. Venkatachalam, M. A., D. B. Jones, H. G. Rennke, D. Sandstrom, and Y. Patel. 1981. Mechanism of proximal tubule brush border loss and regeneration following mild renal ischemia. Lab. Invest. 45:355365 .

14. Hanley, M. J. 1980. Isolated nephron segments in a rabbit model of ischemic acute renal failure. Am. J. Physiol. 239:F17-F23.

15. Burke, T. J., R. E. Cronin, K. L. Duchin, L. N. Peterson, and R. W. Schrier. 1980. Ischemia and tubule obstruction during acute renal failure in dogs: mannitol in protection. Am. J. Physiol. 238:F305-F314.

16. Hanley, M. J., and K. Davidson. 1981. Prior mannitol and furosemide infusion in a model of ischemic acute renal failure. Am. J. Physiol. 241:F556-F564.

17. Burke, T. J., P. E. Arnold, and R. W. Schrier. 1983. Prevention of ischemic acute renal failure with impermeant solutes. Am. J. Physiol. 244:F646-F649.

18. Schrier, R. W., P. E. Arnold, J. A. Gordon, and T. J. Burke. 1984. Protection of mitochondrial function by mannitol in ischemic acute renal failure. Am. J. Physiol. 247:F365-F369.

19. Burke, T. J., P. E. Arnold, J. A. Gordon, R. E. Bulger, D. C. Dobyan, and R. W. Schrier. 1984. Protective effect of intrarenal calcium membrane blockers before or after renal ischemia: functional, morphological, and mitochondrial studies. J. Clin. Invest. 74:1830-1841.

20. Mandel, L. J., and R. S. Balaban. 1981. Stoichiometry and cou- 
pling of active transport to oxidative metabolism in epithelial tissues. Am. J. Physiol. 240:F357-F371.

21. Balaban, R. S., S. Soltoff, J. M. Storey, and L. J. Mandel. 1980. Improved renal cortical tubule suspension: spectrophotometric study of $\mathrm{O}_{2}$ delivery. Am. J. Physiol. 238:F50-F59.

22. Farber, J. L., K. R. Chien, and S. Mittnacht, Jr. 1981. The pathogenesis of irreversible cell injury in ischemia. Am. J. Pathol. 102:271281 .

23. Siegel, N. J., W. B. Glazier, I. H. Chaudry, K. M. Gaudio, B. Lytton, A. E. Baue, and M. Kashgarian. 1980. Enhanced recovery from acute renal failure by the postischemic infusion of adenine nucleotides and magnesium chloride in rats. Kidney Int. 17:338-349.

24. Gaudio, K. M., T. A. Ardito, H. F. Reilly, M. Kashgarian, and N. J. Siegel. 1983. Accelerated cellular recovery after an ischemic renal injury. Am. J. Pathol. 112:338-346.

25. Soltoff, S. P., and L. J. Mandel. 1984. Active ion transport in the renal proximal tubule. I. Transport and metabolic studies. J. Gen. Physiol. 84:601-622.

26. Mandel, L. J., and E. Murphy. 1984. Regulation of cytosolic free calcium in rabbit proximal renal tubules. J. Biol. Chem. 259:1118811196.

27. Jones, D. P., and F. G. Kennedy. 1982. Intracellular oxygen supply during hypoxia. Am. J. Physiol. 243:C247-C253.

28. Mandel, L. J., T. G. Riddle, and J. C. LaManna. 1977. A rapid scanning spectrophotometer and fluorometer for in vivo monitoring of steady-state and kinetic optical properties of respiratory enzymes. In Oxygen and Physiological Function. F. F. Jobsis, editor. Professional Information Library, Dallas. 79-89.

29. Chance, B., and C. M. Williams. 1956. The respiratory chain and oxidative phosphorylation. Adv. Enzymol. Relat. Areas Mol. Biol. 17:65-134.

30. Bergmeyer, H. U., E. Bernt, and B. Hess. 1963. Lactic dehydrogenase. In Methods of Enzymatic Analysis. H. U. Bergmeyer, editor. Academic Press, Inc., New York. 736-743.

31. Layne, E. 1957. Spectrophotometric and turbidimetric methods for measuring proteins. Methods Enzymol. 3:447-454.

32. Takano, T., S. P. Soltoff, S. Murdaugh, and L. J. Mandel. 1985. Intracellular respiratory dysfunction and cell injury in short-term anoxia of rabbit renal proximal tubules. Kidney Int. 27:275.

33. Soltoff, S. P., and L. J. Mandel. 1984. Active ion transport in the renal proximal tubule. III. The ATP dependence of the sodium pump. J. Gen. Physiol. 84:643-662.

34. Mittnacht, S., Jr., S. C. Sherman, and J. L. Farber. 1979. Reversal of ischemic mitochondrial dysfunction. J. Biol. Chem. 254:9871-9878.

35. Nakazawa, T., and T. Nunokawa. 1977. Energy transduction and adenine nucleotides in mitochondria from rat liver after hypoxic perfusion. J. Biochem. 82:1575-1583.

36. Miyahara, M., E. Okimasu, H. Mikasa, S. Terada, H. Kodama, and K. Utsumi. 1984. Improvement of the anoxia-induced mitochondrial dysfunction by membrane modulation. Arch. Biochem. Biophys. 233: 139-150.

37. Chien, K. R., J. Abrams, A. Serroni, J. T. Martin, and J. L. Farber. 1978. Accelerated phospholipid degradation and associated membrane dysfunction in irreversible, ischemic liver cell injury. J. Biol. Chem. 253:4809-4817.

38. Katz, A. M., and H. Reuter. 1979. Cellular calcium and cardiac cell death. Am. J. Cardiol. 44:188-190.

39. Murphy, E., J. F. Aiton, C. R. Horres, and M. Lieberman. 1983. Calcium elevation in cultured heart cells: its role in cell injury. Am. J. Physiol. 245:C316-C321.

40. Gmaj, P., H. Murer, and R. Kinne. 1979. Calcium ion transport across plasma membranes isolated from rat kidney cortex. Biochem. $J$. 178:549-557.

41. Doucet, A., and A. I. Katz. 1982. High affinity Ca-Mg-ATPase along the rabbit nephron. Am. J. Physiol. 242:F346-F352.

42. Rossi, C. S., and A. L. Lehninger. 1964. Stoichiometry of respiratory stimulation, accumulation of $\mathrm{Ca}$ and phosphate, and oxidative phosphorylation in rat liver mitochondria. J. Biol. Chem. 239:39713980.

43. Lotscher, H. R., K. H. Winterhalter, E. Carafoli, and C. Richter. 1980. The energy-state of mitochondria during the transport of $\mathrm{Ca}^{2+}$. Eur. J. Biochem. 110:211-216.

44. Snowdowne, K. W., and A. B. Borle. 1984. Measurement of cytosolic free calcium in mammalian cells with aequorin. Am. J. Physiol. 247:C396-C408.

45. Gaudio, K. M., T. A. Ardito, H. F. Reilly, M. Kashgarian, and N. J. Siegel. 1983. Accelerated cellular recovery after an ischemic renal injury. Am. J. Pathol. 112:338-346.

46. Weinberg, J. M., M. Clark, and H. D. Humes. 1984. Effects of exogenous ATP on tubule cell ATP levels. Clin. Res. 32:459A. (Abstr.) 